\title{
In Vitro Evaluation of the Efficacy of Three Different Remineralizing Agents on Artificial Enamel Lesions in Primary Teeth: A Comparative Study
}

\author{
Sameer Punathil ${ }^{1}$, Mohamad R Alqhtani ${ }^{2}$, Preethi Sathydevi ${ }^{3}$, Moaz M Almoteb ${ }^{4}$, S Preethi Archana ${ }^{5}$, \\ Niranjana Arumugasamy ${ }^{6}$
}

\begin{abstract}
Aim: The aim of the present study was to assess the effectiveness of three various remineralizing agents on artificial enamel lesions in deciduous teeth. Materials and methods: Eighty primary teeth that were implicated for extraction were taken from patients of 4 to 14 years of age. Every specimen was subjected to air drying followed by the creation of $3 \times 3 \mathrm{~mm}$ window positioned on the central surface of the coronal portion of the tooth to restrict the area of investigation. A digital $\mathrm{pH}$ meter was utilized to formulate a demineralizing solution by checking the $\mathrm{pH}$ before and following formulation of the solution. A total of 80 specimens (20 in every group) were allocated to three of the following experimental groups and one control group: group I: control, group II: tricalcium phosphate, group III: casein phosphopeptide-amorphous calcium phosphatefluoride (CPP-ACPF), and group IV: calcium sucrose phosphate (CaSP). Specimens in every group were subjected to treatment with the assigned remineralizing substance once in 24 hours for 14 days. Confocal laser scanning microscopic (CLSM) evaluation of the samples was performed to assess the baseline and posttreatment remineralization as well as demineralization.

Results: CPP-ACPF group $(110.73 \pm 0.11)$ displayed the greatest mean remineralization depth, in pursuit by the calcium orthophosphate complex (CaSP) group ( $122.19 \pm 0.28)$, tricalcium phosphate group (126.87 \pm 0.15$)$ as well as the control group (158.46 \pm 0.07$)$. These differences amid the investigational groups for remineralization were significant. The greatest depth $(\mu)$ area of remineralization was seen in the CPP-ACPF group $(50.29 \pm 0.06)$ in pursuit by the CaSP group $(36.70 \pm 0.17)$ as well as the tricalcium phosphate group ( $33.29 \pm 0.06)$. This difference amid the remineralizing agents was statistically significant.

Conclusion: Amid the confines of the limitations of the current research, it may be concluded that the three remineralizing agents studied, exhibited a remineralization capability on the artificially induced lesions in enamel. CPP-ACPF exhibited the greatest remineralization capability in comparison with the CaSP and tricalcium phosphate groups.

Clinical significance: Dental caries is an unalterable course that leads to everlasting loss of dental hard tissues with eventual formation of a cavity. Off late, numerous techniques have centered on applying remineralizing substances to early lesions due to dental caries, aiming at arresting demineralization while encouraging remineralization. Such remineralizing substances form an atmosphere that is superconcentrated with calcium and phosphate, thereby forcing these ions to diffuse into the unoccupied areas, thereby avoiding further loss of minerals.
\end{abstract}

Keywords: Artificial enamel lesion, Demineralization, Primary teeth, Remineralization.

The Journal of Contemporary Dental Practice (2021): 10.5005/jp-journals-10024-3215

\section{INTRODUCTION}

Presently, dental caries is thought to be a result of repeated demineralizing and remineralizing phases instead of a singledirectional demineralizing procedure. In the early stages before frank cavity formation, demineralization occurs due to mineral loss from hard tissues of the teeth. Such incipient lesions can be repaired when there is a reversal of the calcium/phosphate gradient with their diffusion within the tooth instead of toward the outside, a procedure called remineralization. ${ }^{1}$

Presence of calcium/phosphate in large amounts within saliva serves as the main mineral reservoir within the oral milieu. Calcium/ phosphate as well as hydroxyl ions within saliva plays a pivotal role in the formation of apatite. The remineralizing process begins as the $\mathrm{pH}$ of saliva rises above the crucial pH level. Calcium and phosphate binding to enamel with aid of saliva, fluorides, or additional substances lead to restoration of fluoridated hydroxyapatite (HA) in addition to fluorapatite in their crystalline forms. ${ }^{2}$

Lately, a variety of remineralizing substances have been launched, a majority containing fluoride, calcium, and phosphate ions in diverse types and levels. Applying substances capable of causing remineralization to the dental hard tissues intends to
${ }^{1}$ Department of Pediatric and Preventive Dentistry, Sree Anjaneya Institute of Dental Sciences, Calicut, Kerala, India

${ }^{2}$ College of Dentistry, Prince Sattam Bin Abdulaziz University, Alkharj, Saudi Arabia

${ }^{3}$ Department of Conservative Dentistry and Endodontics, KMCT Dental College, Calicut, Kerala, India

${ }^{4}$ Department of Dental Services, King Khalid Hospital and Prince Sultan Centre for Health Care, Al-Kharj, Riyadh, Saudi Arabia

${ }^{5}$ Department of Pediatric and Preventive Dentistry, Adhiparasakthi Dental College and Hospital, Chengalpattu, Tamil Nadu, India

${ }^{6}$ Department of Pediatric and Preventive Dentistry, Sri Ramakrishna Dental College and Hospital, Coimbatore, Tamil Nadu, India

Corresponding Author: Sameer Punathil, Department of Pediatric and Preventive Dentistry, Sree Anjaneya Institute of Dental Sciences, Calicut, Kerala, India, Phone: +91 9526227454, e-mail: sameeralshifa@gmail.com

How to cite this article: Punathil S, Alqhtani MR, Sathydevi P, et al. In Vitro Evaluation of the Efficacy of Three Different Remineralizing Agents on Artificial Enamel Lesions in Primary Teeth: A Comparative Study. J Contemp Dent Pract 2021;22(11):1308-1313.

Source of support: Nil

Conflict of interest: None

(C) The Author(s). 2021 Open Access This article is distributed under the terms of the Creative Commons Attribution 4.0 International License (https://creativecommons. org/licenses/by-nc/4.0/), which permits unrestricted use, distribution, and non-commercial reproduction in any medium, provided you give appropriate credit to the original author(s) and the source, provide a link to the Creative Commons license, and indicate if changes were made. The Creative Commons Public Domain Dedication waiver (http://creativecommons.org/publicdomain/zero/1.0/) applies to the data made available in this article, unless otherwise stated. 
regulate the process of demineralization and remineralization being influenced by the micro-atmosphere of teeth. ${ }^{3}$

The introduction of casein phosphopeptide-amorphous calcium phosphate-fluoride (CPP-ACPF) as a remineralizing substance dates back to 1998. It comprises nanocomplexes of the milk protein casein phosphopeptide (CPP) plus casein phosphopeptide (ACP). As per the hypothesis, it increases remineralization of incipient dental caries by sustaining an atmosphere that is saturated with vital minerals and simultaneously causes hampered colonization of tooth surfaces by caries causing microorganisms. ${ }^{4}$

Calcium/phosphate in soluble type can be provided by a calcium orthophosphate complex (CaSP) that is a nonhygroscopic and delicately pulverized white material tasting a neutral bland. It is constituted by $11.5 \%$ of calcium by dry mass. Utilizing the frequent ion affects, CaSP reduces enamel solubility in an acidic environment and upscales the rate of remineralization. ${ }^{5}$

A $0.21 \% \mathrm{w} / \mathrm{w}$ sodium fluoride $(\mathrm{NaF})$ anticaries dentifrice, the Clinpro Tooth Crème, contains 950 ppm fluoride along with functionalized tricalcium phosphate (f-TCP). Fluoride coupled with TCP causes enhanced remineralization that equates to surface microhardness as well as fluoride uptake and reduces the quantity of fluoride necessary to attain the identical degree of remineralization (RML). ${ }^{6}$

The primary teeth enamel is mineralized to a lesser amount as well as displays a superior diffusion coefficient and is hence more vulnerable to acid dissolution in contrast to the enamel of permanent dentition. Chemical demineralization of teeth is caused by acidic attack through two primary means: dietary acid consumed through food or drink/drugs and microbial attack from bacteria present in the mouth. During an acidic attack, or a typical demineralization regime, chemical dissolution of both the organic and inorganic matrix components takes place. ${ }^{7}$ Early childhood caries affecting the deciduous teeth commonly appears as white spot lesions, necessitating vigorous preventive procedures that are capable of causing remineralization of such areas, indispensable for their resolution. ${ }^{8}$ Therefore, the current research was performed to appraise the effectiveness of three different remineralizing agents on artificial enamel lesions in deciduous teeth.

\section{Materials and Methods}

\section{Collection of Samples}

The current in vitro research was performed in the Department of Pediatric and Preventive Dentistry, Sree Anjaneya Institute of Dental Sciences, Kerala. Eighty deciduous molar teeth that were implicated for extraction under local anesthesia were taken from patients of 4 to 14 years of age. Prior to commencement, an informed consent was sought from the parents in writing, and ethical approval was obtained. The inclusion criterion of the study was teeth having $\geq 1$ intact tooth surface, absence of evident dental caries, areas of hypoplasia, stains, or white spot lesions (WSLs). Teeth with developmental defects or any other crown deformities and teeth with major restoration were excluded from the study. Following removal, individual teeth were subjected to cleansing, washing beneath water followed by storing in isotonic saline.

\section{Sample Size Calculation and Sample Preparation}

The sample size calculation was done by using the following formula:

$$
n=\frac{Z_{21}-\alpha / 2}{d^{2}}
$$

where $n$ was the required sample size, $z_{1-\alpha / 2}$ was a constant, its value for a two-sided test was 1.96 for $95 \%$, and $d$ was absolute precision $20 \%=0.2$. After sample size calculation, 80 sample teeth were chosen for this research in accordance with the inclusion criteria. Each selected tooth was subjected to thorough ultrasonic cleaning followed by polishing with pumice slurry employing a polishing brush/rubber cup. In order to restrict the region of study, following air drying of the specimens, $3 \times 3 \mathrm{~mm}$ size window region was positioned in the central part of the coronal surface of the tooth. The remaining part was subjected to painting with nail varnish and allowed to dry.

\section{Preparation of Demineralizing Solution}

A digital $\mathrm{pH}$ meter was utilized to formulate a demineralizing solution by checking the $\mathrm{pH}$ before and following the formulation of the solution. The demineralizing solution thus prepared was composed of $2.2 \mathrm{mM}$ calcium chloride, $\mathrm{CaCl}_{2} \cdot 2 \mathrm{H}_{2} \mathrm{O}, 2.2 \mathrm{mM}$ monosodium phosphate, $\mathrm{NaH}_{2} \mathrm{PO}_{4} \cdot 7 \mathrm{H}_{2} \mathrm{O}, 0.05 \mathrm{M}$ lactic acid, and $\mathrm{C}_{3} \mathrm{H}_{6} \mathrm{O}_{3}$. Finally, the $\mathrm{pH}$ was set at 4.5 using $50 \%$ sodium hydroxide. ${ }^{9}$ Every specimen was placed in recently formulated $15 \mathrm{~mL}$ of demineralizing solution. Demineralization was performed for a period of 72 hours at a temperature of $37^{\circ} \mathrm{C}$ in an incubator, following which the postdemineralization scores were documented. The specimens were subjected to thorough rinsing with deionized water and reserved for a washout duration of 24 hours.

\section{Remineralizing Procedure}

A total of 80 specimens ( 20 in every group) were allocated to three of the following experimental groups and one control group.

Group I: Control-Distilled water (Aquarch, Ahmedabad, India) Group II: Tricalcium phosphate (Clinpro ${ }^{\mathrm{TM}}$, Clinpro Tooth Creme, 3M ESPE Dental Products, Ontario, Canada)

Group III: CPP-ACPF (GC Tooth Mousse Plus, GC Corporation, Tokyo, Japan)

Group IV: Calcium sucrose phosphate (CaSP) (Toothmin ${ }^{\text {TM }}$ paste, Abbott Healthcare, Mumbai, India)

Specimens in every group were subjected to treatment with the assigned remineralizing substance once in 24 hours for 14 days. The substances to be thus tested were constantly applied to the tooth surface inside the window region with the aid of a disposable cotton tip applicator for 3 minutes. Specimens were subsequently subjected to washing with deionized water followed by the placement in artificial saliva $\left(3.90 \mathrm{mM} \mathrm{Na}{ }_{3} \mathrm{PO}_{4}, 4.29 \mathrm{mM} \mathrm{NaCl}{ }_{2}\right.$ $17.98 \mathrm{mM} \mathrm{KCl}, 1.10 \mathrm{mM} \mathrm{CaCl}, 0.08 \mathrm{mM} \mathrm{MgCl}, 0.50 \mathrm{mM} \mathrm{H}_{2} \mathrm{SO}_{4}$ $3.27 \mathrm{mM} \mathrm{NaHCO}_{3}$, distilled water, and the $\mathrm{pH}$ was set at 7.2) that was preserved at a constant temperature. The artificial saliva was replaced every 24 hours, prior to immersing the recently treated specimens.

\section{Evaluation of the Area of Remineralization}

Confocal laser scanning microscopic (CLSM) evaluation of the samples was performed to assess the baseline and posttreatment remineralization as well as demineralization. Sectioning of the teeth was done using hard tissue microtome to obtain specimens that were 150-200 microns thick. The specimens belonging to the experimental as well as control groups were subjected to storage in Rhodamine B dye [0.1 $\mathrm{mM}$ of Rhodamine $B$ solution was prepared by adding $23.95 \mathrm{mg}$ of Rhodamine $B$ dye to $500 \mathrm{~mL}$ of distilled water] for an hour. Rhodamine B solution infiltrates within the demineralized tooth area without penetrating intact tooth tissues. 
The sections thus stained were fixed and mounted on a frosted glass slide with $80 \%$ glycerol mountant. Using $10 \times$ intent, argon laser at 50\% power was formed using a $488 \mathrm{~nm}$ excitation wavelength. Confocal slits were placed at $25 \mu \mathrm{m}$ using the $515 \mathrm{~nm}$ long-pass filter. The areas planoparallel to the specimens prepared surface were scanned.

The intact enamel (Untreated Specimen) looked pitch black close to 0 fluorescence (grayscale value of approx. 0 ). The lesions thus stimulated in the demineralized specimens showed estimated autofluorescence. Nevertheless, because of the absorption of the Rhodamine dye $(0.1 \mathrm{mM})$, the permeable area of demineralization looked to have substantial contrast (higher gray values). Specimens that displayed reduced fluorescence (smaller gray values indicating reduced porous areas in addition to the dispersion of dye/additional mineral) had remineralized. Images thus taken were subjected to calibration for linear depth of fluorescence plus average/complete lesional fluorescence employing software. The values thus obtained were documented in tabular form (Figs 1 to 4).

\section{Statistical Analysis}

The mean and standard deviation were calculated using SPSS software (version 20.0). Comparison amid the different groups of remineralizing substances was performed with the one-way

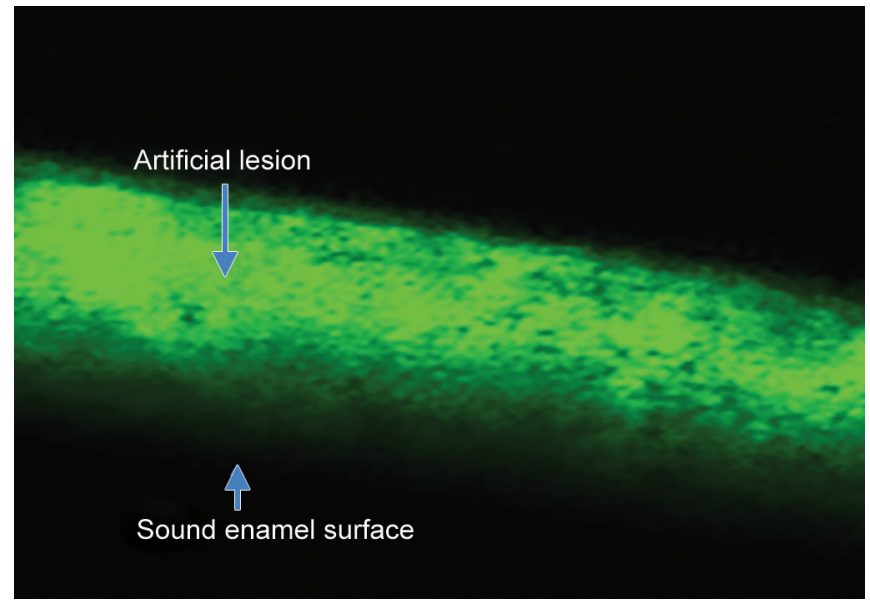

Fig. 1: Image of demineralized areas of sectioned tooth

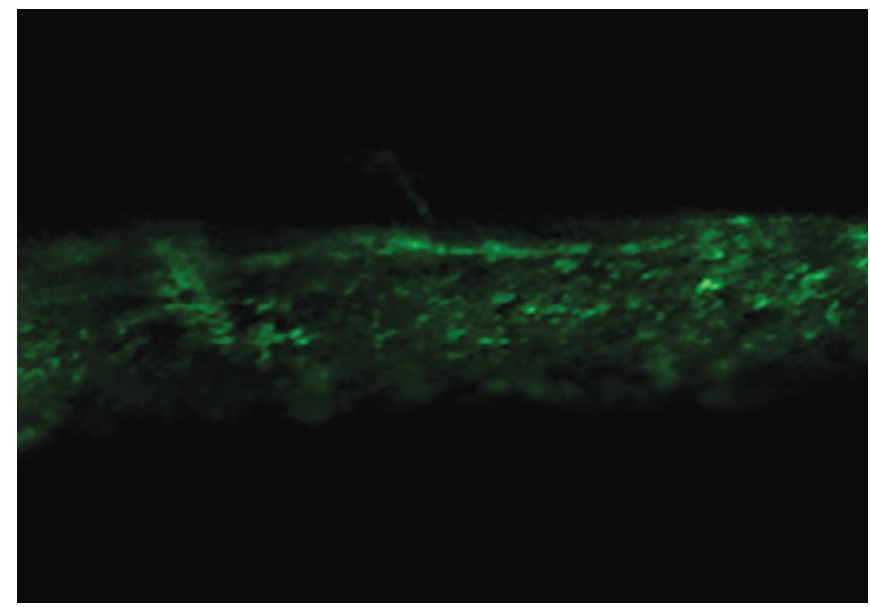

Fig. 2: Image of remineralized area with tricalcium phosphate remineralizing agent analysis of variance (ANOVA). Statistical significance was set at a $p$ value $<0.05$.

\section{Results}

The mean demineralization depth prior to applying the remineralizing agents belonging to the investigational groups is depicted in Table 1. $161.23 \pm 0.14$ was the mean depth of demineralization in the control group; $160.16 \pm 0.09$ was for the tricalcium phosphate group, $161.02 \pm 0.17$ for CPP-ACPF as well as $158.89 \pm 0.11$ for the CaSP group. These differences amid the investigational groups were not significant.

The mean remineralization depth after applying the remineralizing agents belonging to the investigational groups is portrayed in Table 2. CPP-ACPF group $(110.73 \pm 0.11)$ displayed the greatest mean remineralization depth, in pursuit by the CaSP group $(122.19 \pm 0.28)$, tricalcium phosphate group $(126.87 \pm 0.15)$ as well as the control group (158.46 \pm 0.07$)$. These differences amid the investigational groups for remineralization were significant.

The greatest depth $(\mu)$ area of remineralization was seen in the CPP-ACPF group $(50.29 \pm 0.06)$ in pursuit by the CaSP group $(36.70 \pm 0.17)$ as well as the tricalcium phosphate group

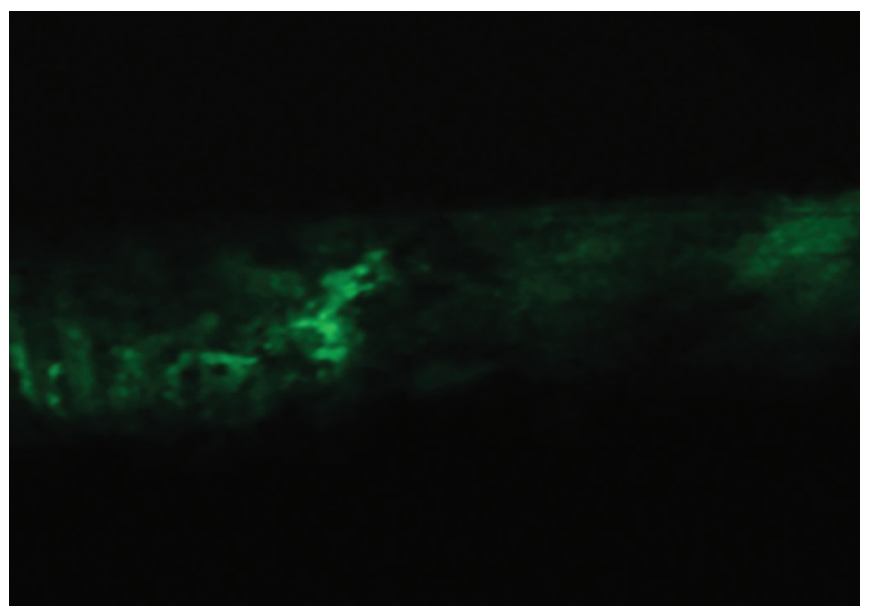

Fig. 3: Image of remineralized area with CPP-ACPF remineralizing agent

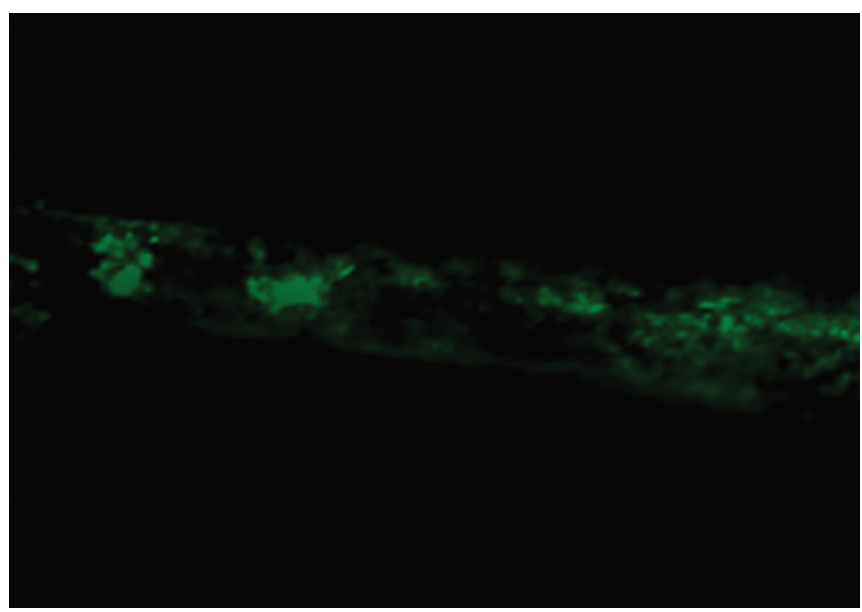

Fig. 4: Image of remineralized area with CaSP remineralizing agent 
(33.29 \pm 0.06$)$. This difference amid the remineralizing substances was statistically significant as depicted in Table 3.

Table 4 shows the assessment of the mean depth of remineralization on the whole, among the investigational groups. With the exception of tricalcium phosphate group plus the CaSP group, a statistically significant difference $(p<0.05)$ was present in every group.

Table 1: Evaluation of the mean depth of demineralization before the application of remineralizing agents among the experimental groups

\begin{tabular}{lcccc}
\hline Study groups & $n$ & Mean $\pm S D(\mu)$ & Fvalue & pvalue \\
\hline Group I: Control & 20 & $161.23 \pm 0.14$ & & \\
$\begin{array}{l}\text { Group II: Tricalcium } \\
\text { phosphate }\end{array}$ & 20 & $160.16 \pm 0.09$ & 29.214 & 0.596 \\
Group III: CPP-ACPF & 20 & $161.02 \pm 0.17$ & & \\
Group IV: CaSP & 20 & $158.89 \pm 0.11$ & & \\
\hline
\end{tabular}

Table 2: Evaluation of the mean depth of remineralization after the application of remineralizing agents among different study groups

\begin{tabular}{lcccc}
\hline Study groups & $n$ & Mean $\pm S D(\mu)$ & Fvalue & pvalue \\
\hline Group I: Control & 20 & $158.46 \pm 0.07$ & & \\
$\begin{array}{l}\text { Group II: Tricalcium } \\
\text { phosphate }\end{array}$ & 20 & $126.87 \pm 0.15$ & 26.181 & 0.001 \\
Group III: CPP-ACPF & 20 & $110.73 \pm 0.11$ & & \\
Group IV: CaSP & 20 & $122.19 \pm 0.28$ & & \\
\hline
\end{tabular}

\section{Discussion}

Striking equilibrium between the process of demineralization and remineralization is the main factor that helps prevent dental caries. Traditionally, the basis of conservative management for dental caries concerned caries removal followed by restoration. Nevertheless, after several years of investigation, the key emphasis in efficient treatment of dental caries is the timely identification of lesions followed by the utilization of noninvasive procedures. An effort to attain this reversed stage has been triumphantly made by means of dentifrices. The noninvasive management of initial lesions caused by dental caries through remineralization has important benefits in clinical therapy, and remineralization eliminates the usual breach flanked by preventive and other interventional techniques like surgery. Fundamental to this visualization is the capacity to identify carious lesions in a timely manner and properly measure the amount of mineral loss, making sure that the right therapy is started. ${ }^{10}$

Acid-producing microorganisms release organic acids that penetrate within enamel as well as the organic matrix of dentin into the tissues beneath. As the acids reach vulnerable sites on the crystalline surface, the dissolution of minerals occurs into an adjacent aqueous atmosphere. Enamel demineralizes at the crucial $\mathrm{pH}$ of around 5.5. In case the calcium/phosphate quantities are subjected to restoration at superconcentrated levels, the minerals infiltrate inside the teeth, depositing a novel layer that resists acidic attacks on crystalline remnants in lesions that are not cavitated. ${ }^{11}$ The enamel layer on the outmost surface has been documented to exhibit the greatest resistance to dissolution. Two hypotheses that have been put forth regarding the production of the highly

Table 3: Comparison of depth $(\mu)$ area before and after the application of remineralizing agents among the experimental groups

\begin{tabular}{lccc}
\hline & $\begin{array}{c}\text { Depth }(\mu) \text { area before the } \\
\text { application of remineralizing } \\
\text { agents }\end{array}$ & $\begin{array}{c}\text { Depth }(\mu) \text { area after the } \\
\text { application of remineralizing } \\
\text { agents }\end{array}$ & $\begin{array}{c}\text { Depth }(\mu) \text { area of } \\
\text { difference after } \\
\text { remineralization }\end{array} \quad \begin{array}{c}\text { Fvalue } \\
p \text { value }\end{array}$ \\
\hline Group I: Control & $161.23 \pm 0.14$ & $158.46 \pm 0.07$ & $33.29 \pm 0.07$ \\
Group II: Tricalcium phosphate & $160.16 \pm 0.09$ & $126.87 \pm 0.15$ & $50.29 \pm 0.06$ \\
Group III: CPP-ACPF & $161.02 \pm 0.17$ & $110.73 \pm 0.11$ & $3.314 \quad 0.001$ \\
Group IV: CaSP & $158.89 \pm 0.11$ & $122.19 \pm 0.28$ & $36.70 \pm 0.17$ \\
\hline
\end{tabular}

Table 4: Overall comparison of mean depth of remineralization among the study groups

\begin{tabular}{llcc}
\hline Study groups & \multicolumn{1}{c}{ Comparison with } & Mean difference $($ I-J) & Significance \\
\hline Control & Tricalcium phosphate & 31.59 & 0.001 \\
& CPP-ACPF & 47.73 & 0.001 \\
& Calcium sucrose phosphate (CaSP) & 36.27 & 0.001 \\
Tricalcium & Control & -31.59 & 0.001 \\
phosphate & CPP-ACPF & 16.14 & 0.001 \\
& Calcium sucrose phosphate (CaSP) & 4.68 & 0.082 \\
CPP-ACPF & Control & -47.73 & 0.001 \\
& Tricalcium phosphate & -16.14 & 0.001 \\
& Calcium sucrose phosphate (CaSP) & -11.46 & 0.001 \\
& Control & -36.27 & 0.001 \\
& Tricalcium phosphate & -4.68 & 0.082 \\
& CPP-ACPF & 11.46 & 0.001 \\
\hline
\end{tabular}


mineralized surface layer on the early lesions include: fluoride being deposited along with other salivary ions and the flow of minerals/ ions toward the outside from the surface below the lesion into the more superficial layers. ${ }^{12}$

The primary teeth enamel is mineralized to a lesser amount as well as displays a superior diffusion coefficient and is hence more vulnerable to acid dissolution in contrast to the enamel of permanent dentition. Early childhood caries that affects the primary dentition frequently manifests as white spot lesions, and aggressive preventive therapy for remineralization of these lesions is essential for their reversal. ${ }^{8}$ In the current research, the CPP-ACPF group exhibited the greatest remineralization capacity in comparison with CaSP and tricalcium phosphate groups. These results are in accordance with the research by Thimmaiah et al. ${ }^{10}$ which documents that CPP-ACPF enhances noteworthy remineralization of early lesions of dental caries. Likewise, other research by Elsayad et al. ${ }^{13}$ as well as Rathi et al. ${ }^{14}$ shows that CPPACPF enhances anticaries activity with the advantage of releasing calcium/phosphate in the neighboring atmosphere at the time of acidic confrontation. These are outstanding liberation vehicles accessible for slow discharging amorphous forms to accumulate calcium, phosphate as well as fluoride on the surface of the teeth. Nanohydroxyapatite possesses the capability of remineralization of the tooth structure. In addition to being hydrophilic, it presents a larger surface area as compared to the conservative hydroxyapatite crystals. Therefore, they discern superior wet ability leading to the formation of a thin though tough layer on the surface of enamel that binds to the tooth surface.

Certain research found superior ability of remineralization exhibited by the CaSP group as compared to the CPP-ACPF group. Menon et al. ${ }^{15}$ arrived at a conclusion that salivary concentration of calcium undergoes a noteworthy enhancement with CaSP leading to greater calcium accumulation on the teeth. Added to this, CaSP decreases depositing of plaque on the surface of teeth. Kaur et al. ${ }^{16}$ assessed the remineralization capability of dissimilar substances, and it was documented that there were no significant differences in the remineralizing capacity of CPP-ACPF and CaSP. Mildly enhanced remineralization rate was exhibited by CaSP vs CPP-ACPF.

In the current research, lowest ability to remineralize was seen in tricalcium phosphate group vs the other investigational groups. These results are in harmony with the results of Ebaa Alagha and Amira Mohammad Samy ${ }^{17}$ who found that the most excellent remineralization capacity was shown by CPP-ACP group (2.67) in contrast to tricalcium phosphate group (2.07). The investigated groups showed significant differences $(p=0.019)$. Kamath et al. ${ }^{8}$ conducted a research on early dental caries lesions and assessed the efficiency of dissimilar remineralizing agents such as tricalcium phosphate TCP, CPP-ACFP, as well as nanohydroxyapatite. They found that all the studied substances had remineralizing effects. TCP had shown supreme remineralization potential owing to more quantities of calcium/phosphorus ions along with fluoride ions within the saliva, thus rendering it an apt remineralizing agent that enhances remineralization of the incipient dental caries.

The limitations of this research arise from the period of study that is 14 days to assess remineralization. Within this tenure, artificially induced lesions did not undergo complete remineralization, and hence, this period of applying remineralizing substances in this research may not be applicable for complete remineralization. Also, the procedure of remineralization in vitro is not alike in vivo within the mouth. Continuing clinical trials are essential to institute the effectiveness of remineralizing substances in remineralization of WSLs in deciduous dentition within in vivo circumstances.

\section{Conclusion}

Within the limitation, the present study concluded that all three remineralizing agents showed remineralization potential on artificial enamel lesions. But CPP-ACPF group showed the superior remineralization potential compared to CaSP and tricalcium phosphate.

\section{References}

1. Abou Neel EA, Aljabo A, Strange A, et al. Demineralizationremineralization dynamics in teeth and bone. Int J Nanomedicine 2016;11:4743-4763. DOI: 10.2147/IJN.S107624.

2. Raghu TN, Ananthakrishna S. Remineralization potential of calcium sucrose phosphate on demineralized enamel: results of an in vitro study. J Int Oral Health 2016;8(6):704-708. DOI: 10.2047/jioh08-06-12.

3. Rao A, Malhotra $\mathrm{N}$. The role of remineralizing agents in dentistry: a review. Compend Contin Educ Dent 2011;32(6):26-33. PMID: 21894873.

4. Chole D, Jadhav Y, Kundoor S, et al. Remineralizing agents: minimal invasive therapy a review. IOSR J Dent Med Sci 2016;15(2):64-68. Available from: https://www.iosrjournals.org/iosr-jdms/papers/ Vol15-issue2/Version-10/J0152106468.pdf

5. Raksha $B$, Mithra $H$. An overview on remineralizing agents. Indian J Appl Res 2015;6(1):331-336. DOI: 10.36106/ijar.

6. Karlinsey RL, Mackey AC, Stookey GK, et al. In vitro assessments of experimental $\mathrm{NaF}$ dentifrices containing a prospective calcium phosphate technology. Am J Dent 2009;22(3):180-184. PMID: 19650601.

7. Hara A, Zero D. The caries environment: saliva, pellicle, diet, and hard tissue ultrastructure. Dent Clin North Am 2010;54(3):455-467. DOI: 10.1016/j.cden.2010.03.008.

8. Kamath P, Nayak R, Kamath SU, et al. A comparative evaluation of the remineralization potential of three commercially available remineralizing agents on white spot lesions in primary teeth: an in vitro study. J Indian Soc Pedod Prev Dent 2017;35(3):229-237. DOI: 10.4103/JISPPD.JISPPD_242_16.

9. Patil N, Choudhari S, Kulkarni S, et al. Comparative evaluation of remineralizing potential of three agents on artificially demineralized human enamel: an in vitro study. J Conserv Dent 2013;16(2):116-120. DOI: 10.4103/0972-0707.108185.

10. Thimmaiah $C$, Shetty $P$, Shetty SB, et al. Comparative analysis of the remineralization potential of CPP-ACP with fluoride, tri-calcium phosphate and nano hydroxyapatite using SEM/EDX-an in vitro study. J Clin Exp Dent 2019;11(12):e1120-e1126. DOI: 10.4317/ jced.55941.

11. Featherstone JD. The continuum of dental caries-evidence for a dynamic disease process. J Dent Res 2004;83(Spec No C):C39-C42. DOI: 10.1177/154405910408301s08.

12. Rajendran R, Kunjusankaran RN, Sandhya R, et al. Comparative evaluation of remineralizing potential of a paste containing bioactive glass and a topical cream containing casein phosphopeptideamorphous calcium phosphate: an in vitro study. Pesqui Bras Odontopediatria Clín Integr 2019;19:e4668. DOI: 10.4034/ PBOCl.2019.191.61.

13. Elsayad I, Sakr A, Badr Y. Combining casein phosphopeptideamorphous calcium phosphate with fluoride: Synergistic remineralization potential of artificially demineralized enamel or not? J Biomed Opt 2009;14(4):044039. DOI: 10.1117/1. 3210780.

14. Rathi N, Baid R, Baliga S, et al. Comparative evaluation of nanohydroxyapatite preparation and calcium sucrose phosphate on microhardness of deciduous teeth after iron drop exposure-an in-vitro study. J Clin Exp Dent 2017;9(4):579-583. DOI: 10.4317/jced.53677. 
15. Menon LU, Varma RB, Kumaran P, et al. Efficacy of a calcium sucrose phosphate based toothpaste in elevating the level of calcium, phosphate ions in saliva and reducing plaque: a clinical trial. Contemp Clin Dent 2018;9(2):151-157. DOI: 10.4103/ccd.ccd_562_17.

16. Kaur G, Sanap AU, Aggarwal SD, et al. Comparative evaluation of two different remineralizing agents on the microhardness of bleached enamel surface: results of an in vitro study. Indian J Dent Res 2015;26(2):176-179. DOI: 10.4103/0970-9290.159154.

17. Alagha E, Samy AM. Effect of different remineralizing agents on white spot lesions. Maced J Med Sci 2021;9(D):14-18. DOI: 10.3889/ oamjms.2021.5662. 